\title{
Investigating the Correlation between the Life and Religious Attitudes with Psychological Well-Being in Nurses Working in Health Centers at Qom Universities of Medical Sciences in 2014
}

Nafiseh Habibian 1

Reza Ahmadi²

Abasali Vashian ${ }^{3}$

\section{Seyyed Moazam Mortazavi ${ }^{4}$}

Tahmineh Dadkhah-Tehrani*5

\begin{abstract}
${ }^{1}$ Department of Psychology, Arak Branch, Islamic Azad University, Arak, Iran 2Department of Counseling, Shahrekord Branch, Islamic Azad University, Shahrekord, Iran ${ }^{3}$ Religion and Health Research Center, Qom University of Medical Science, Qom, Iran ${ }^{4}$ Department of Laboratory Sciences, Faculty of Paramedical Sciences Kurdistan University of Medical Sciences, Sanandaj, Iran ${ }^{*}$ Department of Midwifery, School of Nursing and Midwifery, Qom University of Medical Sciences, Qom, Iran ${ }^{*}$ Corresponding Author: Tahmineh Dadkhah-Tehrani, E-mail: dadkhah.qums@gmail.com
\end{abstract}

Doi:10.5901/mjss.2015.v6n6s4p168

\section{Abstract}

Nurses are the most important group to give care services in health system. They may face with various stresses related to their job that may cause physiological problems. Many factors can influence their psychological health .the present study aimed at demonstration the relationship between religious attitude and life attitude with psychological wellbeing. This correlational cross sectional research has been conducted on 237 nurses working at governmental hospital of Qom with branch sampling in 1393. The data was collected by 4 questionnaires: demographic, psychological wellbeing, life attitude and religious attitude. Life attitude was at medium level in $56 / 5 \%(n=134)$ of participants as well as religious attitude and psychological wellbeing were at medium level in $53 / 6 \%(n=127)$. Correlational Pearson test showed that total score of both life attitude and religious attitude had significantly positive relationships with psychological wellbeing (respectively $r=+0 / 34, p<0 / 01 ; r=+0 / 30, p<0 / 01$ ). Life attitude and religious attitude can influence positively on psychological wellbeing.

Keywords: life attitudes, religious attitudes, psychological well-being, nurses working.

\section{Introduction}

Given the importance of issue and the challenges, with which a person is faced in taking efforts to do the life affairs and realize his unique talents, this question always raises: What is the factor for creating the happiness and well-being in people?

The employees, who work in hospitals, are the most important providers of health system service, and thus this activity has put their constant work encountered with psychological, physical health and mental problems. Therefore, taking measures to enhance the status of mental health in nurses is significantly important. The mental health is the main principle of overall health in human in addition to his physical health. The mental health means the successful implementation of mental performance which results in constructive activities, communication with other people and ability to adapt to learning changes and self confidence (Johnson, 2003). Following these theories and positive psychology movement, which emphasize on the existence of positive characteristics and development of individual capabilities, a group of psychologists has utilized the psychological well-being except for the mental health term because they believe that this term bring the positive dimensions to mind (Ryff \& Singer, 1998). Psychological well-being refers to the physical health and the perception and feeling which a person has about his health (psychological health); and a person will be in total health status in terms of well-being as far as the positive affection dominates the negative one. It is in fact the individual overall life assessment which is created based on the personal goals and access to them (Huebner 
et al, 2000). The psychological well-being is among the normal concepts and structures of positive psychology (Ryff, 1989). According to this group, the lack of disease is not sufficient for the sense of health, but the sense of life satisfaction, the adequate development, efficient interaction with world, the positive energy and creation, favorable link and relationship with community and a positive development are among the characteristics in healthy individuals (Karademas, 2007). In this regard, the models are developed such as Jahoda's model, Diener subjective well-being model, and Ryff's six- factor model of psychological well-being which have focused on individual abilities except for emphasizing on the illness and weakness in defining and describing the mental health (Compton, 2001). Ryff and Keyes (1995) Well-being and positive mental health or psychological well-being of Keys (1995) presented the well-being psychological model or positive mental health model. Based on Ryff's model, the psychological well-being is composed of 6 factors: self-acceptance, positive relations with others, self determination, purpose in life, personal growth and environmental mastery. According to the reason for attention to mental health, the physical, psychological and social health is essential for human growth and development. Therefore, creating and retaining the healthy idea, the ability to build healthy and intimate relationships with peers and purposeful life are significantly important especially in today's growing population where the people are under the unfavorable and stressful conditions of life more than past (Wong et al, 2001). Since a large part of individual lives is spent in the workplace or school environment and in totally different conditions from house, most of the life events and activities have a profound effect on their physical and mental health. The religious-spiritual aspects and reliance on God and doing the religious practices and beliefs are among the methods by which the Islamic system employees make their mental conditions stable and fresh. The nearness to God and attention to working life spirituality lead to the peace, satisfaction and mental health (Kun, 2001).

The religion is among the most effective factors in human history. The religious attitude refers to the monotheistic coherent beliefs which consider the God as the center of affairs and regulate the human values, morals, customs and behavior with each other, nature and themselves. The spirituality has a significant relationship with mental health and people with religious orientation are more reasonable in cognition and more compromise with environmental conditions and have higher mental health (Johnson, 2004).

According to the recent studies on the psychology of religion, there is an evidence of relationship between the mental health and psychological well-being with religion. Some of the studies by Park et al (1990) have concluded that the religion can play a moderating role in influencing the stressful situations.

In fact, the religion is the privilege aspect of human and there is no nation who has been able to live without the religion during the human history. The religion is discussed by pioneers such as James, Freud, Jung et al, and later the thinkers such as Allport and Ross (1967) explained the religion. The religion can be helpful for mental health as a unifying principle and massive force.

However, the important point is that there has not been any period in human history without religious belief, and the religious beliefs deal with rational and logical justification; and any common sense requires accepting it wholeheartedly. In fact, the human religious belief gives him a sense of control and increases his mental health (Spilka, 1989).

The positive attitude to life is another factor which affects the well-being and mental health. The positive attitude to life refers to the individual trust in purposive life framework which gives his life valuable meaning (Battista and Almond, 1973). The positive life attitude, which is the purpose and meaning of life, is in fact among the most important religious, administrative, philosophical and psychological issues. The psychologists such as Allport, Levin, Erik ferm, Erikson, and Jung have implicitly discussed the purpose and meaning of life. The human does not only lives with well being, but the sense of emptiness and finding no meaning in life threaten the individual mental health and sometimes predisposing him to anxiety and depression in today's world (Nelson-Jones, 2003).

Nowadays, the absence of disorder symptoms is not only considered in definition of mental health, but also the development and movement towards the growth and utilizing the purpose in life are among the most important criteria for mental health (Seligman \& Csikszentmihalyi, 2000). In this regard, the utilization of meaning and purpose in life reflects the mental health and increases the individual ability to do the affairs. In newer sources, the meaning is assumed as an idea which lies in an object or event. In the field of human action, this concept includes the intention to do the behavior and refers to the nature of behavior (Mascaro et al, 2004).

Given the importance of positive attitude in finding the meaning in human life, it can be found out that the religious behavior and beliefs can have positive impact on life meaningfulness. However, the human perfection and its achievement are the extents which are different in people in terms of choosing their goals and attitudes towards them. The framework, which is chosen by a person in life, represents his understanding of life structure and philosophy and it is an approach for inferring the meaning in life; and this human perception of life is based on the accurate selection of appropriate formula and rule for life. 
Since the early 1970, an empirical analytical program was developed about the spiritual happiness and was effective in encouraging a large group of sociologists and psychologists to scientifically study this vital aspect after revision of mental health definition and proposing the issues such as the well-being, happiness and spirituality (Pepitone \& Saffiotti, 1997).

Numerous researchers have studies in this field and introduced special factors and dimensions; and any person with these aspects and dimensions will have an extent of psychological well-being. Given the importance of psychological well-being in people especially the nurses, who play the important roles in the health and well-being in other people and are directly associated with their health and lives, we have decided to investigate the correlation between the life and religious attitudes with psychological well-being in nurses at Qom University of Medical Sciences.

In this regard, Koenig et al investigated the effect of religious activities on improving the depression in patients with heart failure. 1000 patients, aged over 50 years with depression based on the interviews and psychiatrist's comments, were participated in this research. There was no significant difference between different religions in terms of recovered depression. The results indicate that those, who participated in religious activities, had been recovered from depression and had higher mental health (Koenig, 2007).

Ferguson (1993) has concluded in his research and studies that the spiritual-religious experiences will often lead to the shift in individual moral values. Therefore, this shift will increase the distance from the materialism and lead to the assistance, friendship, positive attitude to life and finally the individual mental health.

Hackney and Sanders (2003) have also investigated the correlation between spirituality and mental health and found that the people with stronger religious-spiritual beliefs gain higher scores in tests of mental and physical health.

In a research entitled "The spirituality, religion, and clinical outcomes in patients recovering from an Acute Myocardial Infarction", Blumenthal et al (2007) have investigated 503 patients suffering from the heart failure and depression with no enough social support. This study indicates that there is a significant relationship between the spirituality and religious activities such as the prayer. The rate of depression has an inverse relationship with religious activities. Therefore, the researcher is seeking to examine his research with these hypotheses.

Main hypothesis: There is a significant correlation between the life and religious attitudes with psychological wellbeing.

Sub-hypotheses:

1- There is a significant correlation between the life attitude and psychological well-being.

2- There is a significant correlation between the religious attitude and psychological well-being.

The research has the sectional-correlative type. The statistical population in this study consists of all nurses working in health centers of Qom University of Medical Sciences. Sampling is done by applying the formula for determining the sample size of cross-sectional studies (descriptive and analytical) with correlation type and its compatibility with table, and the sample size is estimated equal to $250 \mathrm{~N}$ is measured for quantitative data and two scopes hypothesized in order to estimate the required sample size in each group at confidence level of $95 \%$ and test power of $80 \%$. Sampling is done by cluster sampling in this study, so that all public hospitals of Qom Province are identified including Shahid Beheshti, Kamkar, Nekoei, Izadi, Alzahra and Hazrat Masoumeh hospitals. After preparing the program of monthly shifts in wards of these hospitals, a sample is selected from the list of nurses in each shift through a random numbers table. The inclusion criteria of research are as follows: The physical and mental health, being employed in health and administrative sectors and public hospitals of city, to have at least a year of experience, to have at least an associate's degree, the full-time and permanent employment in the hospital.

\section{Method and Materials}

A demographic questionnaire and three questionnaires are utilized to investigate the religious attitude, life attitude and psychological well-being.

The religious attitude is assessed by Clark and Stark's religious attitude questionnaire. This questionnaire has a quite long history and contains 26 articles and 4 belief, experience, consequence, and ritual dimensions. Its external validity is obtained equal to $61 \%$ by Pearson correlation coefficient and its total reliability is approved by Split-half of $75 \%$ and Cronbach's alpha of $78 \%$. Its validity is estimated by measuring the correlation. This questionnaire has the following dimensions: belief, experience, consequence, and ritual dimensions.

He has developed this test to assess the rate of meaning seeking in life. The life attitude index includes 28 articles at a five-point Likert scale and 2 subjective and goal achievement sub scales. Its reliability is reported by Battista and Almond (1973) with LRI retest; and the internal consistency by Cronbach's alpha method. This questionnaire consists of two sub scales: "Framework scale", which measures the individual trust in vision or concept in life and selection of goals 
and objectives or views in life based on this vision; and the completion scale which indicates that to what extent a person sees himself perfect or in achieving the framework and ideals of his life.

The psychological well-being is measured by psychological well-being questionnaire introduced by Ryff and Keyes for adults in this study. The subject should respond to questions at a 6-point Likert scale (1: strongly disagree to 6: strongly agree). The internal consistency of the whole test is reported equal to $50 \%$. The psychological well-being is a multi-component concept and includes 1- self-acceptance: positive self-attitude and acceptance of various aspects such as good and bad characteristics and positive feeling about the past life; 2- Positive relations with others: Sense of satisfaction with relationship with others and understanding the importance of these dependencies; 3- Self determination: The sense of independence and affecting the external events and active role in behavior; 4- Controlling the environment: The sense of dominating the environment, controlling the external activities and taking the advantage of surrounding opportunities; 5- Purposive life: To have purpose in life and believe that his present and past life is significant; 6- Personal growth: The sense of continued growth and achievement of new experiences as a creature who has potential talents.

The researcher collected data by receiving the relevant license from the research committee of university and went to the selected hospitals. He went to the wards of hospital according to the plans of wards after authorities' approval, and then provided the brief description of research objectives and received the subjects' agreement in an appropriate place and gave the research samples the questionnaires at the end of office hours or shifts. The research subjects responded to the questionnaires after describing different parts of tools and methods for responding to questions. The questionnaires were completed by subjects over a period of two days (in shifts or leisurely at home)

\subsection{Data analysis method}

The data of this research is set in two parts: a) descriptive, b) inferential.

The methods for measuring the correlation between variables are utilized to analyze the obtained data of this research. Pearson's $r$ correlation and Spearman correlation tests are utilized to investigate the correlation between the variables.

\section{Results}

This research investigates the correlation between the religious and life attitudes with psychological well-being. The basic variables include the age, gender, educational level and marital status, and the independent variables include the religious and life attitudes; and the psychological well-being is as the dependent variable.

This study utilizes the descriptive statistics including the calculation of frequency indices and tables as well as measurement of mean and standard deviation in order to achieve the research objectives and analyze data. Pearson test is used to investigate the correlation between the dependent and independent variables and their dimensions.

Table 1. Correlation between the life attitude and psychological well-being by Pearson test.

\begin{tabular}{|ccc|}
\hline & Psychological well being & Pearson correlation test \\
\hline Life attitude & $\mathrm{r}=0.34$ & $\mathrm{P}<0.0001$ \\
\hline
\end{tabular}

Pearson correlation test indicates that there is a statistical significant correlation between the total scores of life attitude and psychological well-being. $(P<0.0001$ and $r=+0.34)$.

Table 2. Correlation between life attitude and psychological well-being by Spearman test.

\begin{tabular}{|ccc|}
\hline & Psychological well being & Spearman correlation test \\
\hline Life attitude & $\mathrm{r}=0.24$ & $\mathrm{P}<0.0001$ \\
\hline
\end{tabular}

Pearson correlation test indicates that there is a statistical significant correlation between the total scores of life attitude and psychological well-being. $(\mathrm{P}<0.0001$ and $r=+0.24)$. 
Table 3. Correlation between the life attitude and sub-scales of psychological well-being by Pearson correlation test.

\begin{tabular}{|ccccccc|}
\hline & $\begin{array}{c}\text { Self- } \\
\text { acceptance }\end{array}$ & $\begin{array}{c}\text { Positive relationships } \\
\text { with others }\end{array}$ & $\begin{array}{c}\text { Self } \\
\text { determination }\end{array}$ & $\begin{array}{c}\text { Environmental } \\
\text { mastery }\end{array}$ & $\begin{array}{c}\text { Purpose } \\
\text { in life }\end{array}$ & $\begin{array}{c}\text { Personal } \\
\text { growth }\end{array}$ \\
\hline \multirow{2}{*}{ Life attitude } & $r=0.274$ & $r=-0.019$ & $r=0.214$ & $r=0.261$ & $r=0.222$ & $r=0.318$ \\
& $P<0.001$ & $P=0.775$ & $P<0.001$ & $P<0.001$ & $P<0.001$ & $P<0.001$ \\
\hline
\end{tabular}

Pearson correlation test about the correlation between the life attitude and subscales of psychological well-being indicates that there is a statistically significant positive correlation between the life attitude and five dimensions, namely, the self-acceptance, self determination, environmental mastery, purpose in life and personal growth at the level of 0.001 and only the sub scale of positive relationships with others has no significant correlation with life attitude.

Table 4. Correlation between the total scores of religious attitude and psychological well-being by Pearson correlation test.

\begin{tabular}{|ccc|}
\hline & Psychological well being & Pearson correlation test \\
Religious attitude & $r=0.3$ & $P<0.0001$ \\
\hline
\end{tabular}

Pearson correlation test about the correlation between the religious attitude and psychological well-being indicates that there is a statistical significant correlation between these two variables $r=+0.30$. Despite the fact that this values in not high, it is considered as a statistical significant correlation at the level of 0.0001 .

Table 5. Correlation between the total scores of religious attitude and psychological well-being by Spearman correlation test.

\begin{tabular}{|lcc|}
\hline & Psychological well being & Spearman correlation test \\
Religious attitude & $\mathrm{r}=0.21$ & $\mathrm{P}<0.01$ \\
\hline
\end{tabular}

Spearman correlation test about the correlation between the religious attitude and psychological well-being indicates that there is a statistical significant correlation between these two variables $r=+0.21$. Despite the fact that this values in not high, it is considered as a statistical significant correlation at the level of 0.01 .

Table 6. Correlation between the life attitude and sub-scales of psychological well-being by Pearson correlation test.

\begin{tabular}{|ccccccc|}
\hline & $\begin{array}{c}\text { Self- } \\
\text { acceptance }\end{array}$ & $\begin{array}{c}\text { Positive relationships } \\
\text { with others }\end{array}$ & $\begin{array}{c}\text { Self } \\
\text { determination }\end{array}$ & $\begin{array}{c}\text { Environmental } \\
\text { mastery }\end{array}$ & $\begin{array}{c}\text { Purpose } \\
\text { in life }\end{array}$ & $\begin{array}{c}\text { Personal } \\
\text { growth }\end{array}$ \\
\hline \multirow{2}{*}{ Religious attitude } & $r=0.259$ & $r=0.093$ & $r=0.095$ & $r=0.188$ & $r=0.148$ & $r=0.345$ \\
& $P<0.001$ & $P=0.155$ & $P<0.146$ & $P<0.001$ & $P<0.023$ & $P<0.001$ \\
\hline
\end{tabular}

Pearson correlation test about the correlation between the religious attitude and subscales of psychological well-being indicates that there is a statistically significant positive correlation between the religious attitude and four dimensions, namely, the self-acceptance, environmental mastery, purpose in life and personal growth at the level of 0.01 , but there is no statistically significant positive correlation between the self determination sub scale and positive relationships with others with religious attitude.

\section{Discussion}

This research is conducted with the aim at investigating the correlation between the life and religious attitude with psychological well-being in nurses working at Qom University of Medical Sciences.

First hypothesis: "There is a significant correlation between the life attitude and psychological well-being".

Pearson correlation test is utilized twice to investigate the first hypothesis: First for investigating the correlation between the total scores of life attitude and psychological well being, and then for investigating the correlation between the total score of life attitude and six sub-scales of psychological well being.

About the correlation between the life attitude and psychological well-being, Pearson correlation test indicates that 
there is a significant positive correlation between these two variables $(r=+0.34)$. Despite the fact that this value is not high, it is considered as a statistical significant correlation at the level of 0.01 . Furthermore, Spearman correlation test indicates that there is a statistical significant correlation between the between the levels of life attitudes and psychological well-being. ( $P<0.0001$ and $r=+0.24)$, therefore, the first hypothesis is approved.

Furthermore, the results of Pearson correlation test indicate that there is a statistical significant positive correlation between the total score of life attitude and five subscales of psychological well-being (subscales of self-acceptance, self determination, environmental mastery, purpose in life and personal growth) at the level of 0.01 , and only the sub scale of positive relationship with others has no significant correlation with life attitude.

Second hypothesis: "There is a significant correlation between the religious attitude and psychological well-being".

Pearson correlation test is also utilized twice to investigate the second hypothesis: First for investigating the correlation between the total scores of religious attitude and psychological well being, and then for investigating the correlation between the total score of religious attitude and six sub-scales of psychological well being.

Pearson correlation test indicates that there is a significant positive correlation between these two variables $(P<0.0001$ and $r=+0.30)$. Despite the fact that this value is not high, it is considered as a statistical significant correlation at the level of 0.01 . Furthermore, Spearman correlation test indicates that there is a statistical significant correlation between the levels of religious attitudes and psychological well-being. $(P<0.01$ and $r=+0.21)$, therefore, the second hypothesis is approved.

Furthermore, Pearson correlation test about the correlation between the religious attitude and sub-scales of psychological well-being indicates that there is a statistical significant positive correlation between the religious attitude and four subscales, namely, the self-acceptance, self determination, environmental mastery, purpose in life and personal growth at the level of 0.01 , but there is no significant correlation between the sub scales, self determination and positive relationship with others with religious attitude.

According to the research by Koenig et al about the impact of religious activities on recovery of depression in patients with heart failure, the results indicate that only those, who have participated in religious activities, have recovered from depression and had higher mental health, but there is no significant difference between different religions in terms of recovered depression; in other words, the type of religion has no impact on this issue (Koenig, 2007).

According to a research entitled "Spirituality, religion, and clinical outcomes in patients recovering from an Acute Myocardial Infarction" by Blumenthal et al, the results indicate that the rate of depression has inverse correlation with religious activities (Blumenthal et al, 2007). The results of their study are consistent with this research.

According to a research by Hackney and Sanders for investigating the correlation between the spirituality and mental health, they have found that those people with stronger spiritual-religious beliefs will gain higher scores in mental and physical health tests (Hackney \& Sanders, 2003). The results of their study also confirm this research.

Furthermore, the research by Ferguson, who concludes that the spiritual experience will lead to achievement of positive attitude and provide the mental health, the survey results are consistent with this research (Ferguson, 1993).

\section{Conclusion}

On the basis of this study, we can conclude that there is a positive correlation between the religious and life attitudes with psychological well-being; and these two variables can be considered as the predictors of psychological well-being.

The researcher has found the results in his research and hopes that these findings will promote the level of mental health in nurses and retention of nurses with higher mental health. According to the research findings, the following recommendations are offered:

1- Strengthening the nurses' religious beliefs to promote their psychological well-being by implementing the appropriate cultural programs.

2- Implementing the programs which help the nurses to have more purposeful life.

3- Selecting and employing the nurses with higher religious attitude.

4- Selecting and employing the nurses who have more positive life attitudes and have clear goals in life.

\subsection{Suggestions for further studies}

It is suggested conducting the studies with following topics according to the findings of this research:

1- Investigating the correlation between the religious and spiritual attitudes.

2- Investigating the correlation between the spiritual attitude and psychological well-being. 


\subsection{Research limitations}

1 - Some research samples could not complete all three questionnaires during the shift, thus the samples are allowed to complete the questionnaires during two desired days in appropriate opportunity or at home.

2 - The results cannot be generalized to non-Muslims.

\subsection{Ethical considerations}

The following ethical considerations are taken into consideration:

1- Obtaining the permission from Qom University of Medical Sciences and the head of healthcare centers.

2- Not forcing the samples to respond to questionnaires.

3- Self-introduction to studied units.

4- Explaining the stages of intervention to volunteers.

5- The confidentiality of collected data in order to comply with ethical laws and principles.

6- Assuring the samples to make the research results available if desired.

7- Thanking the authorities and participants before and after the study.

\section{References}

Allport, G. W., \& Ross, J. M. (1967). Personal religious orientation and prejudice. Journal of personality and social psychology, 5(4), 432. Battista, J., \& Almond, R. (1973). The development of meaning in life.Psychiatry, 36(4), 409-427.

Blumenthal, J. A., Babyak, M. A., Ironson, G., Thoresen, C., Powell, L., Czajkowski, S., ... \& ENRICHD Investigators. (2007). Spirituality, religion, and clinical outcomes in patients recovering from an acute myocardial infarction.Psychosomatic Medicine, 69(6), 501508.

Compton, W. C. (2001). Toward a tripartite factor structure of mental health: Subjective well-being, personal growth, and religiosity. The Journal of psychology, 135(5), 486-500.

Ferguson, D. S. (1993). New Age Spirituality: An Assessment. Westminster: John Knox Press.

Hackney, C. H., \& Sanders, G. S. (2003). Religiosity and mental health: A meta-analysis of recent studies. Journal for the scientific study of religion, 42(1), 43-55.

Huebner, E. S., Funk, B. A., \& Gilman, R. (2000). Cross-sectional and longitudinal psychosocial correlates of adolescent life satisfaction reports. Canadian Journal of School Psychology, 16(1):53-64.

Johnson, B. (2003). Introduction to psychiatry mental health nursing. Philadelphia: Lippincott Williams \& Wilkins.

Johnson, M. R. (2004). Faith, prayer, and religious observances. Clinical cornerstone, 6(1), 17-24.

Karademas E. C. (2007). Positive and negative aspects of well-being: Common and specific predictors. Personality and Individual Differences, 43(2): 277-287.

Koenig, H. G. (2007). Religion and remission of depression in medical inpatients with heart failure/pulmonary disease. The Journal of nervous and mental disease, 195(5), 389-395.

Kun, L. G. (2001). Telehealth and the global health network in the 21 st century. From homecare to public health informatics. Computer methods and programs in biomedicine, 64(3), 155-167.

Mascaro, N., Rozen, D. H., \& Morey, L. C. (2004). The development, validity and clinical valialty of Spiritual Meaning Scale. Personality and Individual Defferences, 37: 845-886.

Nelson-Jones, R. (2003). Theorey and practice of counselling therapy. 3th edition. NewYork: Holt, Rinehart \& Winsto. LTD.

Park, C., Cohen, L. H., \& Herb, L. (1990). Intrinsic religiousness and religious coping as life stress moderators for Catholics versus Protestants. Journal of personality and social psychology, 59(3), 562.

Pepitone, A., \& Saffiotti, L. (1997). The selectivity of nonmaterial beliefs in interpreting life events. European Journal of Social Psychology, 27(1), 23-35.

Ryff, C. D. (1989). Happiness is everything, or is it? Explorations on the meaning of psychological well-being. Journal of personality and social psychology, 57(6):10-69.

Ryff, C. D., \& Keyes, C. L. M. (1995). The structure of psychological well-being revisited. Journal of personality and social psychology, 69(4), 719 .

Ryff, C. D., \& Singer, B. (1998). The contours of positive human health. Psychological inquiry, 9(1): 1-28.

Seligman, M. E. P., \& Csikszentmihalyi, M. (2000). Positive psychology: An introduction. American Psychologist. 55(1): 5-14.

Spilka, B. (1989). Functional and dysfunctional roles of religion: An attributional approach. Journal of Psychology and Christianity, 8(3), 5-15.

Wong, D., Leung, S., So, C., \& Lam, D. (2001). Mental health of Chinese nurses in Hong Kong: The roles of nursing stresses and coping strategies. Online Journal of Issues in Nursing, 5(2), 1-22. 